\title{
Recurrent AIDS-Related Anal Canal Carcinoma
}

National Cancer Institute

\section{Source}

National Cancer Institute. Recurrent AIDS-Related Anal Canal Carcinoma. NCI Thesaurus.

Code C9249.

The reemergence of anal canal carcinoma in HIV-positive patients after a period of remission. 